\title{
Advancement in recycling waste tire activated carbon to potential adsorbents
}

\author{
Umi Fazara Md Ali ${ }^{1,2^{+}}$, Farihahusnah Hussin ${ }^{3}$, Subash C.B. Gopinath ${ }^{1,4}$, Mohamed Kheireddine Aroua ${ }^{3}$, \\ Mohd Hairul Khamidun ${ }^{5}$, Norwahyu Jusoh ${ }^{6}$, Naimah Ibrahim ${ }^{7}$, Syahirah Faraheen Kabir Ahmad \\ ${ }^{1}$ Faculty of Chemical Engineering Technology, Universiti Malaysia Perlis, 02600 Arau, Perlis, Malaysia \\ ${ }^{2}$ Centre of Excellence Biomass Utilization (COEBU), Universiti Malaysia Perlis, 02600 Arau, Perlis, Malaysia \\ ${ }^{3}$ Research Centre for Carbon Dioxide Capture and Utilisation (CCDCU), School of Engineering and Technology, Sunway University, Bandar Sunway \\ 47500, Selangor, Malaysia \\ ${ }^{4}$ Centre of Excellence for Nanobiotechnology and Nanomedicine (CoExNano), Faculty of applied Sciences, AIMST University, Semeling, 08100 Kedah, \\ Malaysia \\ ${ }^{5}$ Micropollutant Research Centre, Faculty of Civil and Environmental Engineering, Universiti Tun Hussein Onn Malaysia, Batu Pahat, Malaysia \\ ${ }^{6}$ Chemical Engineering Department, Universiti Teknologi PETRONAS, 32610 Bandar Seri Iskandar, Perak, Malaysia \\ ${ }^{7}$ Faculty of Civil Engineering Technology, Universiti Malaysia Perlis, 02600 Arau, Perlis, Malaysia
}

\begin{abstract}
Waste tires have been identified as one of the contributors to environmental problems and the issue of inadequate landfill spaces. The lack of consistent and systematic approaches such as specific regulations/laws or mechanisms of waste management to waste tires, limited application of technology for recycling waste tires and lack of awareness on the impacts of waste tires problem, make waste tires a source of environmental pollution. Various researches have been conducted on recycling waste tires into polymer bends, and materials to harden concretes, fuels and adsorbent. Researchers suggested that pyrolysis is the current trend of recycling waste tire to harvest the saleable pyrolysis oil and the recycled carbon black. Therefore, this review attempts to compile relevant knowledge about the potential of adsorbent derived from waste tires to be applied in the removal of various types of pollutants like heavy metals, organic pollutants, dye and air/gaseous pollutant. Studies were carried out on revealing the properties and the characteristics of activated carbon derived from waste tire as effective adsorbent which influence the application performance at liquid or gas phase. In addition, the challenges in the production of activated carbon derived from waste tire were discussed.
\end{abstract}

Keywords: Carbon adsorbent, Liquid and Gas, Pyrolysis, Waste Tire

\section{Introduction}

In the new global economy, the disposal of waste tires has become a crucial pressing issue as it contributes to the adverse environmental impacts. Recent researchers have pointed out that the passenger vehicles, trucks, motorcycles and bicycles are the main contributors to waste tire disposal [1]. The waste tire disposal, with current annual worldwide disposal of about one billion scrap tires, is expected to progressively increase as approximately 20 million waste tires are disposed annually [2]. Since waste tires cannot be degraded and contribute to the issue of insufficient landfill spaces, the conven- tional method of waste tire disposal could be a critical environmental concern [3]. Inappropriate treatment of the disposed waste rubber tire can cause many major environmental and health issues. Based to previous research, inappropriate disposal can cause water pipes clogging which can lead to flood risk. Besides that, it also brings the risk of fire, air pollution from the toxic fumes, which contain pollutants such as carbon and sulfur, and also water contamination from the release of oil [4]. According to the research, 57,391 tonnes of waste tires are expected in the leading production countries like Malaysia annually [4] and the ultimate fate of these waste tires to be placed in the landfills. This could deplete the space
This is an Open Access article distributed under the terms of the Creative Commons Attribution Non-Commercial License (http://creativecommons.org/licenses/by-nc/3.0/) which permits unrestricted non-commercial use, distribution, and reproduction in any medium, provided the original work is properly cited.

Copyright (C) 2022 Korean Society of Environmental Engineers
Received September 16, 2021 Accepted December 09, 2021

${ }^{\dagger}$ Corresponding author

E-mail: umifazara@unimap.edu.my

Tel: +60195747680

ORCID: 0000-0001-8881-6626 
in the landfill and causing the issue of inadequate landfill spaces for the domestic wastes from the residents [5]. Hence, the wasted tires shall be prohibited from the landfill to conserve the landfill spaces.

By referring the hierarchy in the waste management, recycling and recovery of these synthetic materials are seem to be the most favour route by most of the countries [6, 7]. Researchers have claim that the waste tires are the energy sources with $30-40 \mathrm{MJ} / \mathrm{kg}$ that can be used exclusively to support the combustion plant [1, 8]. Czajczyńska et al. [8] have discovered that the whole waste tires can be employed in the cement plant to overcome the combusting high temperature of the plant at $1,200^{\circ} \mathrm{C}$. Most recent research shown that waste tires can be recycled by shredding or grinding the tires for producing rubber chips. Several researches have used rubber chips for concrete application, another common product produced from rubber chips such as noise barriers, floatation devices, mats, roofing materials, sports track, and so on [4].

Recent literature offers the contradictory findings about the pyrolysis as the best technology in recovering the wasted tires into the valuable resources for the industrial activities [9] (Fig. 1). Pyrolysis of wasted tires could transform the used tires into gas, oil, steel and recycle carbon black waste (rCB) [10-12]. The common characteristic of the carbon black (CB) is the fluffy and fairly fine traits which provide a comparatively large total surface area [13]. However, CB from the pyrolytic process is not recommended to reuse as a pure CB for the downstream applications including the tire manufacturing industry, as the presence of the inorganic minerals in rCB would downgrade the products superiority, which originally made of pure CB [9].

The generation of rCB as solid waste has contributed to the escalating interest of researchers in the exploration of its sorption efficiency $[14,15]$ thermal and physiochemical properties $[11,16]$ as well as the beneficiation. Fazara et al. [11] has carried out a research and claimed that rCB has a higher specific surface area and oil adsorption number compared to the standard black. Besides that, the particle sizes of rCB is not distributed consistently (heterogeneous) and there is greater value of fines content. By

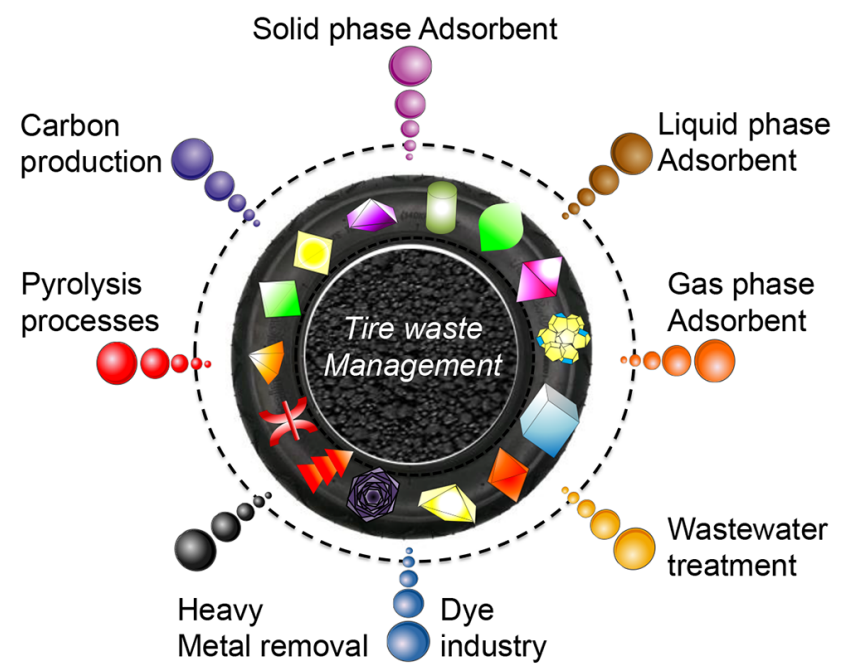

Fig. 1. Potential applications of waste tire recycling. raising the data from the previous researches, several studies have been done by applying the rCB as adsorbents with the modifications in the removal of organics [17-20] and inorganics from the aqueous solution [21-26]. This review focused on the production of the carbons from the waste tire and the potential applications of rCB in industrial sectors.

This review focused on the potential applications of carbon-based material derived from waste tire for the removal of pollutant in liquid and air. To the best of our knowledge there is a lack of research in the open literature focusing on the conversion of waste tires to carbon-based products for gas separation using the pyrolysis technique. Most of the studies so far emphasized on the potential of waste tires as adsorbent in the water and wastewater applications. This is a major research gap in this important and emerging technology, especially the application of pyrolysis technique in gas separation. The findings obtained can be related to recycling of waste into adsorbent and serve as a useful guideline to enhance the process so that it becomes more economically efficient for the removal of liquid and gas phase applications. This review article is relevant to the sustainable development goals on sustainable consumption and production/waste management (SDG 12). The review will have high impact on environment protection and waste management assessment. This review also intends to provide future researchers with the latest research findings, limitations and developments in the carbon-based material from waste tires. This article is structured as follow: After the Introduction in section 1, section 2 concentrates on the comparison of various pyrolysis techniques for carbon-based material production, followed by Section 3 describing the properties and characteristics of waste tires adsorbent. Section 4 presents the potential applications. Section 5 discuss on the challenges of activated carbon production from waste tires. Lastly, the conclusion and future perspectives are detailed out in section 6 .

\section{Uses of Waste Tire in Industry}

Recently, there have been increasing interests in recycling the waste tires in industry and waste tires had been employed in the polymer blend. According to Ramarad et al. [27], blending of waste tire and the polymer could help in reducing the price of polymer synthesis. Yet, the main issue faced in blending waste tires into the polymer blend is the waste tires would degrade the mechanical properties as the waste tires are not bond perfectly with the virgin matrix and modification technologies on the waste tires are needed. Apart from the polymer blend, researchers had also applied waste tire in the concrete. In 2016, Thomas \& Gupta [28] discussed two types of cement which can be mixed with the waste tire, they are fresh cement and hardened concrete with the size-based classification (Table 1). In another study, Kashani et al. [29] reported type of rubber, size of particles and rubber contents significantly effects water absorption and permeability in concrete. The study also observed bigger rubber particles, small rubber particles fill the spaces among natural aggregates and thereby reduce permeability. Moreover, recycled rubber shreds/crumbs have potential to improve the mechanical properties such as tensile and compressive strength. The compressive strength decreased with increasing rubber crumb content [30]. 
Moreover, the workability of the fresh concrete decreases as the amount of crumb rubber grades and proportion added in the concrete increases. The poor inter-particle friction between rubber and other constituent is believed to the main factor contributing to the reduction of the workability of the fresh concrete. Previous researchers had explained that this phenomenon is caused by the high-water absorption of rubber particles within the concrete and further causing a reduction of slump of the rubberized concrete. The researchers also claimed that the rubberized concrete had a lighter density. They showed that the density of the concrete is reduced by $2-11 \%$ depends on the size of rubber used in the rubberized concrete compared to unrubberized concrete (Table 1)

For hardened concrete, Thomas \& Gupta [28] had found that the compressive strength of the concrete decreased compared to the unrubberized concrete. This was further supported by Sofi [31] by pointed out that the compressive strength of the concrete decrease with an increasing percentage of crumb rubber mixed in the concrete. However, there were a few studies convinced that the compressive strength of the concrete was increased when tire rubber ash is utilized in the concrete mixing. Hence, Thomas \& Gupta [28] concluded that the mixing of the crumb rubber shall not exceed $20 \%$ in order to preserve the compressive strength properties.

Waste tires had also been utilized as fuel in the cement industry [8], can be employed as energy source for the incinerator for the cement industry as it contains $>80 \mathrm{wt} \%$ of carbon contents, heating values of $30-40 \mathrm{MJ} / \mathrm{kg}$ as well as low moisture content compared to other solid waste. In addition, Hita et al. [1] had summarized the plants that were potential in utilizing waste tires as energy source.

The applications of waste tire rubber in the form of aggregates or binder in construction industry materials is advantageous includes lowering the $\mathrm{CO}_{2}$ emissions and increasing the greenness of the environment [32, 33]. He et al. [34] modified the surface properties of crumb waste tire rubber by impregnating the raw material with sodium hydroxide $(\mathrm{NaOH})$ solution, potassium permanganate $\left(\mathrm{KMnO}_{4}\right)$ solution and saturated sodium bisulfite sol- ution $\left(\mathrm{NaHSO}_{3}\right)$, respectively and observed that a large number of hydroxyl, carbonyl and sulfonate groups were introduced on the surface of the waste tire. Moreover, the cement containing the modified waste tires control the rate of compressive strength decrement, whereby the compressive strength decreased by $30 \%$, contrast to the untreated waste tire which decreased to $52 \%$. Fraile-Garcia et al. [35] investigated the thermal properties of light concrete construction elements produced using rubber particles from end-of-life tires. They reported that by adding scrap rubber into the composition of concrete will increase the energy and thermal strengths and recommended to be applied in making create material. In a similar study, Chaikaew et al. [36] prepared recycled crumb rubber particles to make concrete material. In order to enhance the mechanical properties of concrete pedestrian blocks, they mixed the waste crumb rubber with short steel fibres. They reported that by adding steel fibre into the rubber particle composition, the resistance to water absorption of blocks increase significantly.

Furthermore, several researchers have explored the influence of recycled waste tire in soil properties. For example, Bekhiti et al. [37] studied the beneficial use of waste tire rubber fiber mix with cement content to assess the strength of the stabilized soil. They discussed the effect of dry density, swelling behavior, unconfined compressive strength (UCS), and ductility behavior. The results showed that dry density decreases when waste tire rubber fiber ratio increases. Waste tire rubber fiber helps to reduce dry density and enhance its compressive strength and soil stability. They found that swell potentials and swelling pressure decrease slowly with increasing waste tire rubber fiber ratio. This parameter is important for the soil, where the focus of the study is to reduce the swell potential of the soil to remove damaging effects due to excessive heave and swell pressures, especially on geotechnical engineering applications. Therefore, waste tire rubber fibers have a beneficial effect when used as support materials to enhance the strength parameters, mitigating the swelling properties in soil. It was proven that waste tire rubber fiber can improve the UCS parameters. The obtained results also showed that ductility in-

Table 1. Classification of Rubber Type Utilized in Concrete Mixing; Effect of Rubber Types Utilized on the Density Reduction; Preparation Parameters for Activated tire Carbon [28]

\begin{tabular}{|c|c|c|c|}
\hline Category & Type of Rubber & Size $(\mathrm{mm})$ & Remark \\
\hline \multirow{4}{*}{$\begin{array}{l}\text { Classification of rubber } \\
\text { type utilized in concrete } \\
\text { mixing }\end{array}$} & Shredded/Chipped & $13-76$ & Involve two-stage shredding \\
\hline & Crumb & $0.425-4.75$ & Grind in the special mill \\
\hline & Ground & $0.075-0.475$ & Two-stage magnetic separation \& screening required \\
\hline & & & Density Reduction (\%) \\
\hline \multirow{4}{*}{$\begin{array}{l}\text { Effect of rubber types } \\
\text { utilized on the density } \\
\text { reduction }\end{array}$} & Coarse Aggregate & & 45 \\
\hline & Fine Aggregate & & 34 \\
\hline & Combined & & 33 \\
\hline & Parameter & & Range \\
\hline \multirow{6}{*}{$\begin{array}{l}\text { Preparation parameters } \\
\text { for activated tire carbon }\end{array}$} & Carbonization Temperature $\left({ }^{\circ} \mathrm{C}\right)$ & & $300-900$ \\
\hline & Carbonization Time (h) & & $0.5-4$ \\
\hline & Activating Agents & & Steam, Steam $/ \mathrm{N}_{2}, \mathrm{KOH} / \mathrm{N}_{2}, \mathrm{CO}_{2}$, Air \\
\hline & Activation Temperature $\left({ }^{\circ} \mathrm{C}\right)$ & & $800-1,000$ \\
\hline & Activation Time (h) & & $1-16$ \\
\hline & Activating Gas Flow Rate (L/min) & & $100-542$ \\
\hline
\end{tabular}


creases with increasing waste tire rubber fiber ratio. Similarly, Shukla et al. [38] conducted a study on the effect of waste tire fibres on swelling behavior and proved that waste rubber fibers successfully improved swelling behavior of the problematic soils.

Liu et al. [39] performed a review study on the application of recycled waste tire in soil and highlighted on compression behavior, shear properties, dynamic properties, thermal properties, hydraulic properties, and morphology characteristics. The use of different types of tire waste such as fibers, shreds, crumbles, particles, and chips can have an outstanding effect on the properties of soils. For example, waste tire shreds are suitable for use to enhance soil properties due to having low density, high shear strength, high hydraulic conductivity, and low thermal conductivity. Moreover, the effect of the particle size of tire waste influences the compression behavior. The compressibility of large size tire shreds was higher than that of the small size tire shreds [40, 41]. For shear properties, the shear strength significantly increases when the waste tire ratio in soil materials increases. There are very limited reports are available in literature on the effect of rubber mixture on shear strength parameters for enhancing soil strength and stability. For the dynamic properties, there is limited information reported in the literature on this parameter. Using rubber-soil mixture will help to increase the shear modulus damping ratio, thus improving dynamic strength [42]. There are few studies reported on the parameters of thermal properties. The combination of waste tire fibers or chips with soil can provide better thermal conductivity and hydraulic conductivity. The rubber-soil mixtures showed good thermal insulation, low thermal conductivity, and high hydraulic conductivity [39]. The surface morphology characteristics of rubber-soil mixtures also play an important role in stability performance. The surface morphology can be determined using Scanning Electron Microscopy (SEM) analysis.

\section{Pyrolysis}

The most recommended method for recycling the waste tires by several researchers was pyrolysis and would produce gas, liquid and solid fractions (Fig. 2). The products produced from pyrolysis were utilized fully in recent industries. The pyrolytic oil contains high calorific values can be recovered and used as alternative fuel for the transportation industry. The presence of the valuable chemicals such as d-limonene within the pyrolytic oil had also draw the attention of the researchers in investigating the values of the pyrolytic oil. However, the high sulphur content, heavy molecules and high concentration of aromatics compounds were the major drawbacks of the pyrolytic oil as these compounds were unacceptable in the environmental perspective [36]. The general pyrolysis process can be divided into three main types (such as flash, fast, and slow pyrolysis) and each type have different reaction duration, heating rate, and main product yield. For flash and fast pyrolysis processes, there are operated at high heating rate, at a medium temperature range, and shorter reaction time. This method produces a minor yield of solid char materials and high yield of fuel oil. Moreover, for slow pyrolysis, this method performed at low heating rate, at a low temperature range, and longer reaction time. This method produces a high yield of solid char materials [43]

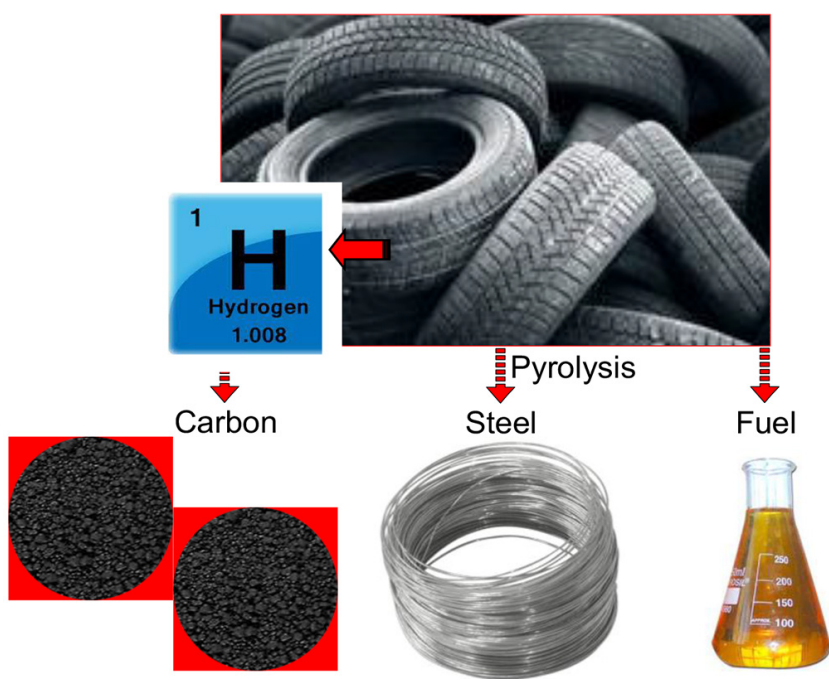

Fig. 2. Pyrolysis in recycling the waste tire. Three major products from the pyrolysis are displayed.

\subsection{Solid Pyrolysis}

The solid waste (char) produced from the waste tire pyrolysis has no further application in current industry. Hence, researchers were in the midst of exploring the potential of the char as useful adsorbents in the wastewater industry. The adsorbents were mainly produced from the char and the original waste tires. There were several ways in formulating the waste tires into the carbon as well as the activation methods are discussed. The previous methods used for preparing the waste tires into adsorbent are summarized in Fig. 2(c).

Mui et al. [44] summarizes that the physical activation of waste tires commonly including utilization of $\mathrm{CO}_{2}$ or steam. Generally, the preparation of the adsorbent from waste tires can be performed in two steps as follows (Thermal pyrolysis at low temperature $\left(400-700^{\circ} \mathrm{C}\right)$ and activation at $\left.800-1,000^{\circ} \mathrm{C}\right)$. The thermal pyrolysis is performed under the helium or nitrogen atmosphere attempting to break down the cross-linkage within the waste tire sample [44, 45]. There is a prominent preparation method is highlighted by Mui et al. [44] as this method demonstrates an adsorbent with $\mathrm{S}_{\mathrm{BET}}$ of $1,260 \mathrm{~m}^{2} / \mathrm{g}$. The pyrolysis and activation of the waste tire is carried out in helium environment with steam at $900^{\circ} \mathrm{C}$ for 1 h. However, the carbon yield for this method is only $9 \%$ from the initial mass.

Demineralization of the waste tire sample can also help in developing the micropores and mesopores. Acid treatment using $\mathrm{HCl}$ solution is essential to remove the inert mineral matter, blocking the pore structure of pyrolyzed waste tire sample. A study has shown that acid treatment of the sample by using $1 \mathrm{M} \mathrm{HCl}$ solution for $24 \mathrm{~h}$ at room temperature before activation under steam/nitrogen (77: 23, v/v) atmosphere contribute to a specific area of $1,119 \mathrm{~m}^{2}$ and mesopore volume of $1.62 \mathrm{~cm}^{3} / \mathrm{g}$.

\subsection{Gas Pyrolysis}

To produce char or activated carbon from waste tires by pyrolysis, there are two stages that need to be carried out. The first step 


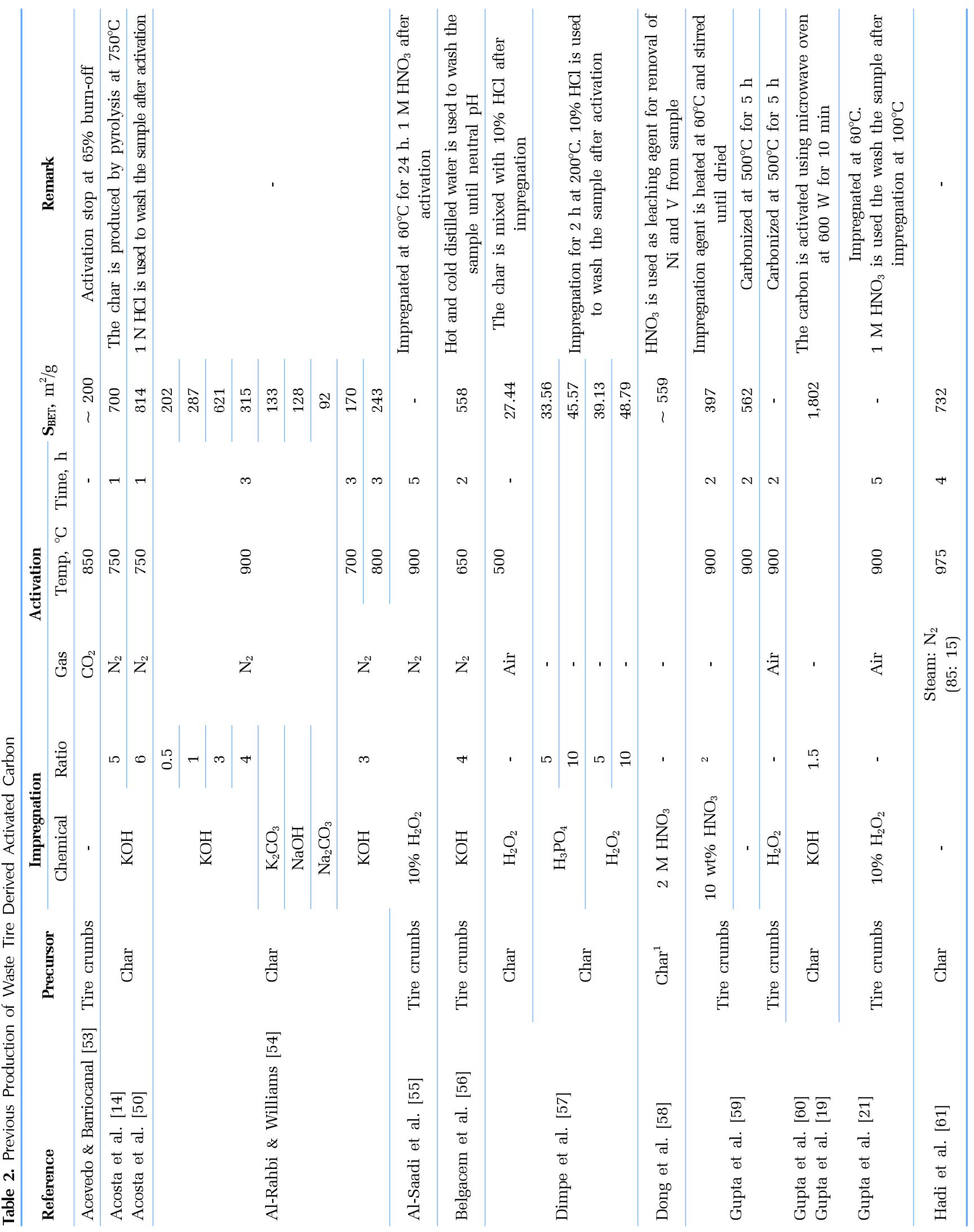




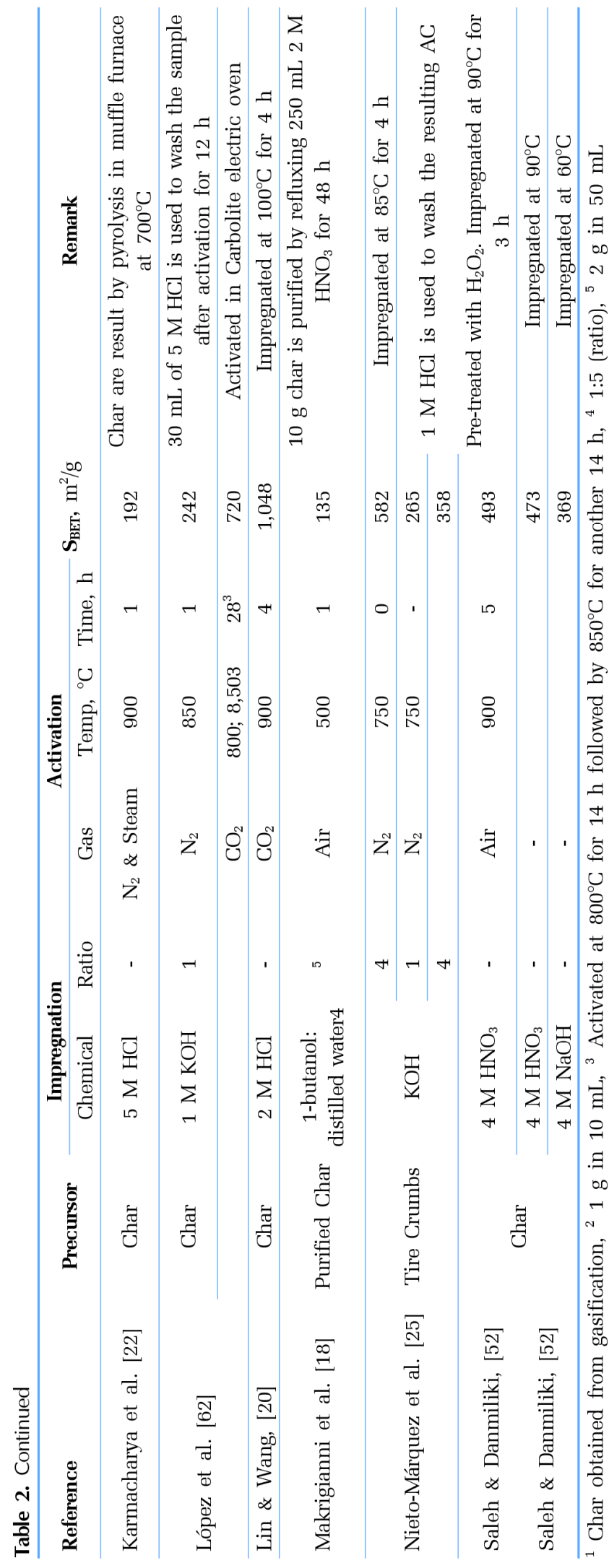

is heating the waste tires in an inert atmosphere (pyrolysis), which produce a yield of char, oil and gas depends on the pyrolysis temperature, heating rate and duration of the pyrolysis process. The second stage is to activate or modify char material with physical or chemical activation to enhance surface properties of activated carbon material. The physical activation normally uses $\mathrm{CO}_{2}$ and/or steam. For chemical activation, acid (such as sulfuric acid, nitric acid) and/or alkali (such as potassium hydroxide and sodium hydroxide) are usually used as an activating agent [46]. This section will only discuss gas pyrolysis or physical activation. Activation of carbon-based material with $\mathrm{CO}_{2}$ will help in increasing the surface area of activated carbon. Mui et al. [44] found that steam is a potential activating agent for preparing activated tire carbon. This study has revealed that tire chars present higher capacity with steam than with $\mathrm{CO}_{2}$. It was proved that steam activation can cover a surface area up to $1,000 \mathrm{~m}^{2} / \mathrm{g}$. On the other hand, Betancur et al. [46] performed a study to produce activated carbon from waste tire using $\mathrm{CO}_{2}$ activation. The benefit of physical activation is that it is a simple and low-cost process and can produce a high surface area. To obtain activated carbons with high surface area and porosity, they investigated the effect of $\mathrm{CO}_{2}$ flow rate, heating temperature, and reaction time. They found that heating temperature and the reaction time showed a significant effect in porosity development. The highest surface area of $414 \mathrm{~m}^{2} / \mathrm{g}$ was obtained at $900^{\circ} \mathrm{C}$ of temperature, $150 \mathrm{~mL} / \mathrm{min}$ of $\mathrm{CO}_{2}$ flow rate and $180 \mathrm{~min}$ of treatment time. Similarly, Choi et al. [47] studied the potential of converting waste tire rubber into activated carbon through pyrolysis with $\mathrm{CO}_{2}$ activation. Pyrolysis was performed at a temperature of $950{ }^{\circ} \mathrm{C}$ using $\mathrm{CO}_{2}$ activation and at $3 \mathrm{~h}$. The highest surface area was $437 \mathrm{~m}^{2} / \mathrm{g}$. Activated chars formed using $\mathrm{CO}_{2}$ activation had high surface areas and porosity. To produce a large surface area of char using steam or $\mathrm{CO}_{2}$ activation, the char has to be heated at a high temperature $\left(>800^{\circ} \mathrm{C}\right)$ to give a successful performance. Steam or $\mathrm{CO}_{2}$ activation can enhance porosity development of the produced char and can produce a high surface area of up to $1,000 \mathrm{~m}^{2} / \mathrm{g}$ [48]. In their latest study, González-González et al. [49] used a combination of chemical activation and physical activation to produce high char yield using pyrolysis. They produced $52 \%$ of char yield from waste tire. The highest surface area was $339 \mathrm{~m}^{2} / \mathrm{g}$ and with an average pore size of $3.6 \mathrm{~nm}$.

\subsection{Carbon Production from Waste Tire}

Carbons can be effectively developed through both chemical and physical activations on the waste tire crumbs or char produced from the waste tire pyrolysis. Only with the physical activation manipulated by researchers was somewhat longer than the methods which utilized both chemical and physical activation processes. Several researches have implemented this technique [44, 45] and overall have concluded that physical activation take longer time than chemical and physical activation process where the $\mathrm{S}_{\mathrm{BET}}$ of the activated carbons mostly found in the range of 200 to $814 \mathrm{~m}^{2} / \mathrm{g}$.

\subsection{Pyrolysis by Microwave Activation}

In previous years, the microwave activation had emerged and became one of the most operative methods in high total surface area AC production. Gupta et al. [19] have recently developed a study 
for the microwave activation on the pyrolyzed char. The pyrolyzed char was primarily impregnated with $\mathrm{KOH}$, at the $\mathrm{KOH}$ to char ratio of 1.5. The resulting carbon was the microwaved at $600 \mathrm{~W}$ for $10 \mathrm{~min}$. The $\mathrm{S}_{\mathrm{BET}}$ of the WT-AC produced by using this method is comparatively high at $1,802 \mathrm{~m}^{2} / \mathrm{g}$ which is the highest value among the previous studies reviewed.

Precursors of the AC have been identified as a major contributing factor for the quality of AC yielding [50]. The precursor used in the past studies can be mainly categorized into two: tire crumbs and pyrolyzed char. By comparing the activation results from previous studies, the tire crumbs were slightly inferior to the pyrolyzed char as precursor for the AC production. Dimpe et al. [51], used tire crumbs as precursor for production of the WT-AC. The carbon was produced by chemical impregnation of the crumbs in $10 \mathrm{wt} \%$ $\mathrm{HNO}_{3}$ followed by thermal activation at $900^{\circ} \mathrm{C}$ for $2 \mathrm{~h}$. The resulting WT-AC had demonstrated $\mathrm{S}_{\mathrm{BET}}$ of $397 \mathrm{~m}^{2} / \mathrm{g}$, which is lower than the carbon produced by Saleh et al. [52], they employed char as a precursor. The $\mathrm{S}_{\mathrm{BET}}$ of the WT-AC produced was $493 \mathrm{~m}^{2} / \mathrm{g}$ which was chemically impregnated by $4 \mathrm{M} \mathrm{HNO}_{3}$ followed by thermal activation at $900^{\circ} \mathrm{C}$ for $5 \mathrm{~h}$. By comparing both works, the pyrolyzed char can be said to be a better precursor that can be employed for the AC yielding process. However, both studies had kind of different process conditions. Hence, a thorough investigation of the consequence of precursor used on the capability of spawning high-quality WT-AC is required.

By the reason of the poor performance of WT-AC produced in the past research, the WT-AC produced can be blended with the other materials to boost the performance of the carbon. This method is believed to yield a comparable characteristic of AC to the commercial AC in the recent market. A work has been conducted by Acevedo et al. [53] on the production of high-performance AC. In their works, the blend of waste tire and coal are activated and the total surface area of the resulting product is found out to be increase to about $840-1,125 \mathrm{~m}^{2} / \mathrm{g}$ which is proportionate with the commercial AC. The production of the activated carbons derived from the waste tires in the previous studies are summarized in Table 2.

\section{Properties and Characteristics}

\subsection{Surface Area}

Researchers identified that the shape of the adsorption isotherm can provide qualitative information on the adsorption process and the extent of the surface area available to the adsorbate [63]. Fig. 3(a) shows the nitrogen adsorption isotherm of activated carbon that was prepared from waste tire. According to the results in figure, the isotherm exhibits a type IV indicating the presence of mesopores and $\mathrm{H} 4$ hysteresis loop, characteristic of a porous carbon containing slit-shaped pores.

Acevedo et al. [64] reported that carbon-based material from waste tires modified with acid activation, showed insignificant effect on the textural characteristics of the produced adsorbent. Only slight increase in surface area were detected, which may be due to the fact that the pore entrances were blocked by ash. As reported by Saleh et al. [65] a fast adsorption rate of methyl

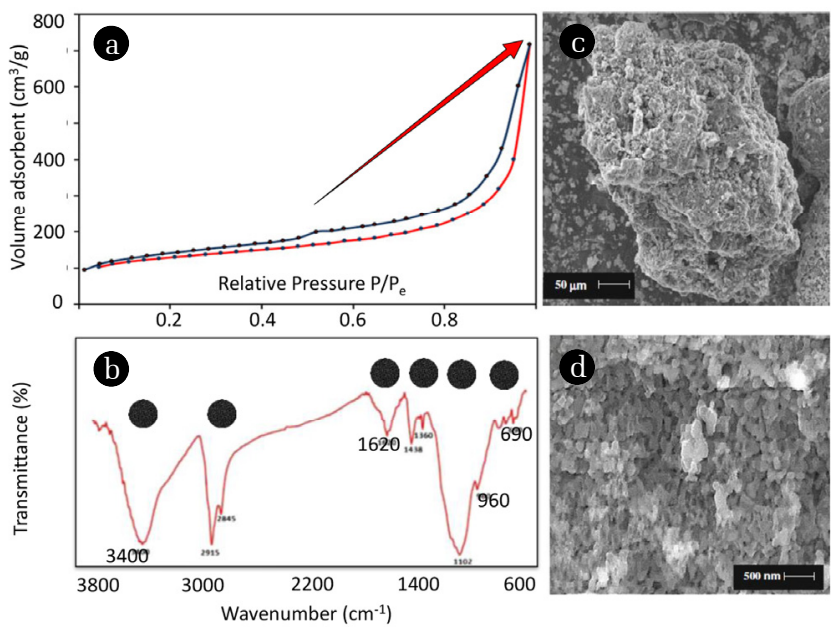

Fig. 3. Characteristics of waste tire activated carbon. (a) Adsorption/desorption isotherms of nitrogen at $77 \mathrm{~K}$ of activated carbon (Adapted from: Acevedo et al. [53]); (b) FTIR spectrum of activated carbon prepared from used tire (Adapt from: Gupta et al. [49]). (c) SEM micrographs of activated carbon (a) x400 (b) x20,000 (Adapted from: Belgacem et al. [56])

orange obtained within $30 \mathrm{~min}$ due to the large surface area of adsorbent $\left(465 \mathrm{~m}^{2} / \mathrm{g}\right)$ resulted in the increase of the number of active sites on the surface of adsorbent which increases the removal efficiency. Similarly, Alexandre-Franco et al. [66] stated that chemical treatment and heat-chemical treatments of used tire rubber do not significantly affect their porosity or decrease it. However, significant porosity developments are achieved only when the used tire rubber is heat-treated using steam activation.

Siddiqui et al. [67] investigated the potential of waste rubber tire as effective adsorbent for nickel ion removal from aqueous solution. The activated carbon was produced by physical and chemical activation method. The surface area of the activated carbon was measured to be $465 \mathrm{~m}^{2} / \mathrm{g}$. This large surface area of the activated carbon could play a vital role in enhancing the removal of $\mathrm{Ni}(\mathrm{II})$. Mashile et al. [68] prepared a magnetic waste tire activated carbon-chitosan (MWTACC) composite as adsorbent for the removal of organic pollutants. The BET surface area of MWTAC was 1387 $\mathrm{m}^{2} / \mathrm{g}$. The results showed that the MWTAC surface area increased with the addition of magnetic nanoparticles. However, after the combination of chitosan and MWTAC, few pores were found clogged. Thus, the BET surface area and pore volume decreased.

\subsection{Surface Functional Group}

Fourier-transform infrared (FTIR) spectroscopy is employed as a powerful tool and applied for qualitative and quantitative identification of chemical species or functional groups located on the activated carbon surface with the assistance of infrared spectra shone on the sample. Gupta et al. [59] analyze the FTIR spectrum of activated carbon prepared from used tire as shown in Fig. 3(b). A large absorption band around 3,400 was presents which corresponded to the stretching vibration of $\mathrm{OH}$ groups that can come from phenol groups that present on the surface or some adsorbed water. While a peak at 2,900 shows - $\mathrm{CH}$ stretching vibration in 
methyl group. In accordance to the results which is the present of weak peak at 2,845 can be analyses as -O- stretching vibration in aldehyde group. A peak at 1,620 can represents $\mathrm{C}-\mathrm{O}$ stretching of carboxyl or carbonyl groups.

Saleh et al. [65] studied the FTIR spectrum of the tire-derived activated carbon using $\mathrm{KBr}$ pellets over the range 4,000-400 $\mathrm{cm}^{-1}$. A strong band around 1,180 $\mathrm{cm}^{-1}$ which corresponded to the carbonyl band to an ester is confirmed present on the surface. The peak at $1,580 \mathrm{~cm}^{-1}$ is attributed to $\mathrm{C}=\mathrm{C}$ double bonds. The peak at $1,710 \mathrm{~cm}^{-1}$ and $1,650 \mathrm{~cm}^{-1}$ are presents the vibrations of carboxyl and carbonyl in acidic oxygen surface groups. The peak at 3,400 $\mathrm{cm}^{-1}$ is ascribed to stretching $(\mathrm{O}-\mathrm{H})$ vibration in hydroxyl groups. The peak at $2,350 \mathrm{~cm}^{-1}$ is ascribed as the alkyne group. Babiker et al. [69] used modified nano-waste tire rubber for investigating the removal of boron by adsorption method. The FTIR peaks of the waste tire rubber samples at $3,037 \mathrm{~cm}^{-1}$ were associated to the polyisoprene vibrations. The presence of $\mathrm{CH}$ symmetrical stretching was observed at 2,917 $\mathrm{cm}^{-1}$. A large absorption band was detected at peak $779 \mathrm{~cm}^{-1}$ which attributed to the functional group. They reported that the two peaks between $1,380 \mathrm{~cm}^{-1}$ and $160 \mathrm{~cm}^{-1}$ are confirmed formation of new peaks due to acid activation treatment. Thus, enhancing the surface properties of the carbon-based material will increase adsorption capacity.

\subsection{Morphology}

Scanning electron microscopy (SEM) was used to examine surface morphology of activated carbon. Belgacem et al. [56] reported that the surface of WT-AC (Fig. 3(c), (d)) shows a heterogeneous distribution of grain and a well-developed porous structure with a small size pore. It also showed presence of cavities and rough texture which can be attributed to the evaporation of volatile compound due to the $\mathrm{KOH}$ reaction at activation temperature under nitrogen atmosphere. Babiker et al. [69] characterized the surface morphology of waste tire rubber sample using scanning electron microscopy (SEM). They showed that the untreated adsorbent presented morphology image with more homogeneity and less rough on the surface than modified adsorbents. While, the morphology image of the modified samples (activation with $\mathrm{HNO}_{3}$ and $\mathrm{H}_{2} \mathrm{SO}_{4}$ ) had a coarser surface and more pores on the surface compared to untreated sample. They concluded that the acid activation would help in enhancing the surface area of the produced samples. Similarly, Mashile et al. [68] observed the surface morphology of adsorbent and showed that a rough surface with more porous structure was detected on the surface of magnetic waste tire activated carbon (MWTAC). As reported by Karmacharya et al. [23] the morphology image of adsorbent showed pore become larger and massive after adsorption of $\mathrm{Cr}(\mathrm{VI})$. Furthermore, the surface texture of the adsorbent is quite agglomerated after adsorption of $\mathrm{Mn}(\mathrm{II})$.

\subsection{X-ray Diffraction (XRD)}

$\mathrm{X}$-ray diffraction (XRD) analysis is a unique method to determine the crystallinity structure of a compound [70]. Mashile et al. [68] analyzed the XRD patterns of waste tire activated carbon, chitosan and magnetic waste tire activated carbon-chitosan (MWTACC). The results showed that the presence of $\mathrm{Fe}_{3} \mathrm{O}_{4}$ at peaks $2 \theta$ with the values of $30.1^{\circ}, 35.4^{\circ}, 43.1^{\circ}, 53.4^{\circ}, 56.9^{\circ}, 62.5^{\circ}$. The XRD patterns observed at peaks $2 \theta=10^{\circ}$ for pure chitosan and $2 \theta=20^{\circ}$ due to crystalline structure. Karmacharya et al. [23] used waste tire rubber for the removal of $\mathrm{Cr}(\mathrm{VI})$ and $\mathrm{Mn}(\mathrm{II})$ ions from aqueous solution. They analyzed the XRD patterns of the produced sample and found broad and intense peaks at $2 \mathrm{q}=24^{\circ}-25^{\circ}$ and $42^{\circ}-43^{\circ}$ matching to amorphous structure. A similar observation was reported by Jusoh et al. [71] The intense peaks observed at $2 \theta=25.0^{\circ}$ and $42.5^{\circ}$ for waste tire adsorbent were associated to amorphous carbon and graphite structure. This confirmed that carbon present in waste tire plays an important role for the adsorption of pollutant. Islam et al. [72] synthesized waste tire rubber by impregnating the raw sample with acid solution and namely as modified waste tire rubber adsorbent (WTR-SO $\mathrm{S}_{3} \mathrm{H}$ ). The results showed that, two peaks at $\sim 24.78^{\circ}$ and $42.17^{\circ}$ corresponding to (002) and (101) reflections of amorphous carbon.

\section{Potential Applications}

An effort taken by the researchers to ensure sustainable management of waste tires through several utilization methods such as reuse, recycling, recovery, and pyrolysis. Waste tires can be recycled and utilized in various applications such as [73-76]:

i. Use in civil application (as filler in road construction, as modifier for asphalt, as a filler in concrete)

ii. Use as adsorbent in water treatment applications (for organic and inorganic removal)

iii. Flue gas cleaning

iv. Air pollution control applications

v. Recovery of oil spills

vi. Energy storage (as fuel source to produce electricity for cement kilns, steam production, electrical energy

In this review, the waste tire-derived activated carbon has been focused on the applications of liquid and gas separation using the pyrolysis technique.

\subsection{Liquid Phase}

\subsubsection{Organic pollutants adsorbent}

WT-AC had been employed by previous researchers in the removal of the organic pollutants that can be found in the recent industry. The performance of the WT-AC in the past studies was persuading comparable removal efficiency as the commercial AC (Fig. 4).

Makrigianni et al. [18] utilized WT-AC prepared by impregnating the pyrolyzed char in 1-butanol: distilled water (1:5) solution and calcinated at $500^{\circ} \mathrm{C}$ for $1 \mathrm{~h}$. The resulting carbon had demonstrated an increasing phenol adsorption of $6 \mathrm{mg} / \mathrm{g}$ (pyrolyzed char) to 51.92 $\mathrm{mg} / \mathrm{g}$. The author stated that it was considerably efficient adsorbent for phenol as the carbon showed the highest adsorption of phenol by comparing the results to the earlier researches performed. The adsorptions of the phenolic compounds on the WT-AC were also performed by Gupta et al. [21] The phenolic compounds that tested in their work were phenol and p-cresol. The carbon that utilized in their work was activated by consuming microwave energy at $600 \mathrm{~W}$ for $10 \mathrm{~min}$. According to Gupta et al. [21] the adsorption of p-cresol $(250 \mathrm{mg} / \mathrm{g})$ on the microwaved WT-AC is higher than the phenol with only $100 \mathrm{mg} / \mathrm{g}$. The author explained that the 


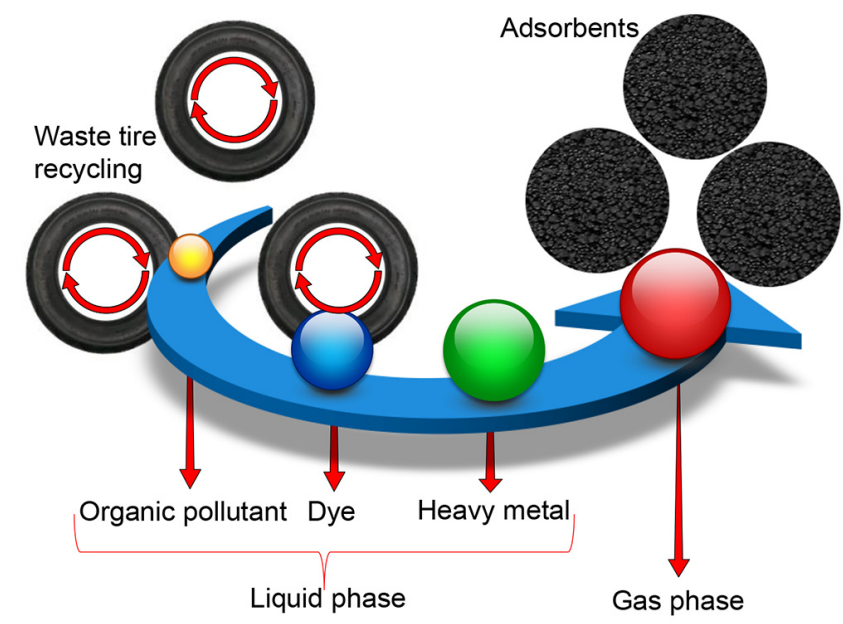

Fig. 4. Waste tire activated carbon applications. The applications of liquid and gas phases are shown.

low adsorption of phenol was due to phenol's high solubility and kinetic rate as its molecular structure is smaller compared to p-cresol. Apart from that, the author also declared that the microwaved WT-AC removal ability on both compounds is superior compared to the other material-derived AC. The other organic compounds such as aniline groups were studied by Gupta et al. [60]. It was found out that the overall performance of the carbons on the removal of the pollutants is as follow: RTAC $_{\mathrm{Ox}}>\mathrm{RTAC}>$ Commercial AC. The performance of the RTAC and commercial AC demonstrated the similar removal ability on the pollutants in the aqueous solution as follow: aniline $>$ p-toulidine $>$ p-anisdine $>\mathrm{p}$-Cl-aniline. The removal percentage of the aniline by the commercial AC reported was $40.53 \%$ compared to the removal percentage of RTAC produced (76.14\%). This exposed that the RTAC produced by only employing physical activation was superior enough in the adsorption of aniline.

\subsubsection{Dye adsorbent}

The performance of the AC is mostly determined by adsorption of the dyes by most of the researchers. The dyes that commonly used for the WT-AC adsorption are methylene blue [18] and methylene blue [20]. The adsorption of the methylene blue studied by Makrigianni et al. [18] shown a maximum MB adsorption of 65.8 $\mathrm{mg} / \mathrm{g}$ for WT-AC. This carbon was chemically activated by $2 \mathrm{M}$ $\mathrm{HNO}_{3}$ followed by the calcination process at $500^{\circ} \mathrm{C}$. The author claimed that WT-AC produced had demonstrated a better performance on the $\mathrm{MB}$ adsorption compared to un-activated pyrolyzed char, which is originally $53.4 \mathrm{mg} / \mathrm{g}$ [62]. However, the performance of the WT-AC produced is incomparable with the commercial AC. Hence, the WT-AC shall be activated in another method to boost the $\mathrm{MB}$ adsorption.

Lin et al. [20] had conducted a study on ethylene blue (EB) adsorption on the WT-AC and the outcomes of the study were delighting. WT-AC resulted from the thermal activation at 900 ${ }^{\circ} \mathrm{C}$ for 4 hours with $\mathrm{CO}_{2}$ flow demonstrate $\mathrm{S}_{\text {BET }}$ of $1048 \mathrm{~m}^{2} / \mathrm{g}$. The optimum EB adsorption of the carbon was $323 \mathrm{mg} / \mathrm{g}$ which is higher than the other AC. WT-AC also performed the removal of the dyes in aqueous solution by adsorption in contrasting behavior.
Acevedo et al. [64] had conducted a research by utilizing activated carbons prepared from wasted tires reinforcing fiber. In their research, they found out that the carbons demonstrated the eminent performance on the removal of Basic Astrazon Yellow 7GLL (AY) in higher $\mathrm{pH}$ while Reactive Rifafix Red 3BN (RR) in a lower $\mathrm{pH}$. The main reason due to the distinctive behavior of the adsorption is the ionization of the compound.

Nogueira et al. [77] prepared effective adsorbents from waste tire rubber for remazol yellow dye removal from aqueous solution. The produced sample was characterized by relatively high ash content $(12.9 \%$ wt), high fixed-carbon content (69.7\% wt), a surface area of $69 \mathrm{~m}^{2} / \mathrm{g}$, and total pore volume of $0.14 \mathrm{~cm}^{3} / \mathrm{g}$. The results showed that adsorption isotherm was better fit for the Langmuir model and the maximum adsorption capacity was $11.9 \mathrm{mg} / \mathrm{g}$. Mashile et al. [68] showed a relatively high removal efficiency up to $100 \%$ removal of parabens and high adsorption capacity of parabens as $85.9 \mathrm{mg} / \mathrm{g}$ and $90.0 \mathrm{mg} / \mathrm{g}$ for methylparaben and propylparaben, respectively using waste tire rubber as adsorbent. The produced sample in this study was claimed to follow pseudo-second-kinetic model. Zhang et al. [78] prepared porous carbons from heavy residue of tire pyrolysis oil for methylene blue removal. The produced porous carbon showed high adsorption capacity of $843.5 \mathrm{mg} / \mathrm{g}$ at $25^{\circ} \mathrm{C}$ and the adsorption equilibrium data fitted the Freundlich isotherm model well.

\subsubsection{Heavy metals adsorbent}

The inorganic pollutants were also employed by most researchers in the determination of the removal capability of WT-AC produced. The inorganic pollutants that were utilized in previous studies were common heavy metal ions (such as $\mathrm{Cu}^{2+}, \mathrm{Zn}^{2+}, \mathrm{Pb}^{2+}, \mathrm{Cr}^{3+}$, $\mathrm{Mn}^{2+}, \mathrm{Hg}^{+}$) that are present in recent wastewater industry. Among the heavy metals, the chromium ions and lead ions were the most-picked ions employed in previous studies due to their toxicity and diverse oxidation number. WT-AC will help in increasing surface area and porosity, thus increasing the adsorption capacity. In addition, important parameters such as $\mathrm{pH}$, mass of adsorbent, contact time, initial concentration of metal ions and activating agents also influenced the removal efficiency and adsorption capacity. The applications of waste tire-based activated carbon to eliminate heavy metal ion from synthetic and wastewater treatment are summarized in Table 3.

\subsection{Gas Phase}

Waste tire derived carbon is potential in the removal of gas phase pollutants such as sulfur dioxide $\left(\mathrm{SO}_{2}\right)$ and nitrogen oxides (NOx). According Nieto-Márquez et al. [91] the waste tire activated with $\mathrm{KOH}$ solution can be utilised in the removal of $\mathrm{SO}_{2}$ in the air. The waste tire activated with $\mathrm{KOH}$ at the mass ratio of $4: 1(\mathrm{KOH}$ : tire weight) demonstrated the highest $\mathrm{SO}_{2}$ uptake with approximately $42.5 \mathrm{mg} \mathrm{SO} / \mathrm{g}$ carbon at $45^{\circ} \mathrm{C}$. An identical research had also carried out by Brady et al. [92], regarding the adsorption kinetics on the $\mathrm{SO}_{2}$ removal. In their research, they found out that the steam-activated sample with total surface area of $1,000 \mathrm{~m}^{2} / \mathrm{g}$ is the most efficient WT-AC in $\mathrm{SO}_{2}$ removal. However, the rapid removal reaction had causing excessive heat generation throughout the $\mathrm{SO}_{2}$ removal process. Another research was also carried out by Al-Rahbi et al. [54] on the NOx uptake by utilizing activated 
Table 3. Summary of WT-AC as Adsorbent for Removal of Heavy Metal lons

\begin{tabular}{|c|c|c|c|}
\hline Heavy metal ions & Adsorption mechanism & Adsorption capacity & References \\
\hline $\begin{array}{l}\text { Chromium, Cr (VI); } \\
\text { Manganese, Mn (II) }\end{array}$ & Langmuir isotherm model and pseudo-second-order kinetics & $\begin{array}{l}14.45 \mathrm{mg} / \mathrm{g}(\mathrm{Cr}(\mathrm{VI})) \\
3.04 \mathrm{mg} / \mathrm{g}(\mathrm{Mn}(\mathrm{II}))\end{array}$ & [23] \\
\hline Fluoride ions & Pseudo-second-order kinetics & $0.95 \mathrm{mg} / \mathrm{g}$ & [79] \\
\hline $\mathrm{Cu}$ (copper ions) & Langmuir isotherm model & $16 \mathrm{mg} / \mathrm{g}$ & [80] \\
\hline Lead, $\mathrm{Pb}(\mathrm{II})$ & Langmuir isotherm model and pseudo-first-order kinetics & $22.35 \mathrm{mg} / \mathrm{g}$ & [81] \\
\hline $\mathrm{Pb}, \mathrm{Hg}, \mathrm{Cu}$ & Langmuir isotherm model and pseudo-first-order kinetics & $52.63 \mathrm{mg} / \mathrm{g}$ & [82] \\
\hline As (III) and As (V) & Freundlich model, and pseudo-second-order kinetics & $\begin{array}{c}\text { Removal efficiency, } \\
\text { As (III) }(99 \%) \text { and As (V) (92\%) }\end{array}$ & [83] \\
\hline $\mathrm{Cu}$ (copper ions) & Freundlich model, and pseudo-second-order kinetics & $1.6 \mathrm{mg} / \mathrm{g}$ & [84] \\
\hline $\mathrm{Cu}, \mathrm{Pb}, \mathrm{Zn}$ & Pseudo-first-order kinetics & Removal efficiency, 92.5\% & [85] \\
\hline $\mathrm{Cu}, \mathrm{Zn}, \mathrm{Pb}, \mathrm{Cr}$ & Pseudo-second-order kinetics & $\begin{array}{c}37.4 \mathrm{mg} / \mathrm{g}(\mathrm{Cu}), 40.2 \mathrm{mg} / \mathrm{g}(\mathrm{Pb}) \\
9.9 \mathrm{mg} / \mathrm{g}(\mathrm{Zn}), 6.3 \mathrm{mg} / \mathrm{g}(\mathrm{Cr})\end{array}$ & [86] \\
\hline $\mathrm{Cr}$ & - & Removal efficiency, 97\% & [87] \\
\hline Iron (Fe (II)) & Pseudo-first-order kinetics & $25.2 \mathrm{mg} / \mathrm{g}$ & [88] \\
\hline $\mathrm{Pb}, \mathrm{Cu}$ & Pseudo-first-order kinetics & $201 \mathrm{mg} / \mathrm{g}(\mathrm{Pb}), 196 \mathrm{mg} / \mathrm{g}(\mathrm{Cu})$ & [89] \\
\hline $\mathrm{Cr}$ & - & Removal efficiency, 92.24\% & [90] \\
\hline
\end{tabular}

waste tire carbon. The most eminent carbon in their work was the $\mathrm{KOH}$ activated waste tire at a mass ratio of 3:1 (KOH: char) and pyrolyzed under $\mathrm{N}_{2}$ atmosphere at $900^{\circ} \mathrm{C}$ yielded $\mathrm{S}_{\mathrm{BET}}$ of 621 $\mathrm{m}^{2} / \mathrm{g}$. This $\mathrm{KOH}$ activated carbon demonstrates NO removal up to $\sim 75 \%$ at $25^{\circ} \mathrm{C}$. Tang et al. [93] prepared different types of municipal solid waste-based carbons for $\mathrm{CO}_{2}$ capture. The optimum conditions were at $25^{\circ} \mathrm{C}$ adsorption temperature, $\mathrm{CO}_{2}$ concentration of $14 \% \mathrm{CO}_{2}$ and flow rate of $100 \mathrm{~mL} / \mathrm{min}$. They reported that the triple components of municipal solid waste-based carbons (pinewood, acrylic textile, and tire) showed the superior adsorption performance, which is $1.522 \mathrm{mmol} / \mathrm{g}$. In a similar study, Krishnaiah et al. [94] conducted a study to modify waste tire derived activated carbon $\mathrm{KOH}$ to enhance $\mathrm{CO}_{2}$ adsorption capacity. They reported that $\mathrm{CO}_{2}$ adsorption was enhanced up to $238.7 \mathrm{mg} / \mathrm{g}$ at $30^{\circ} \mathrm{C}$ using impregnation ratio of 1.5 molar of $\mathrm{KOH}$ solution.

\section{Challenges in Waste Tire Derived Activated Carbon Production}

The major challenge of adsorbent production of waste tire is to increase surface area of activated carbon during activation process. Many studies of derivation of new activated carbon have been published with low surface area, which results in truncated adsorption capacity. In activation phase, the waste tire contacted with an activation gas such as steam, $\mathrm{CO}_{2}, \mathrm{~N}_{2}$ and air at slower rate of heating with isothermal holding. During heating process, reaction between waste tire and activation gas can cause pore opened and enlarge existing pores. The disadvantage of the conventional slow rate heating is greater in energy consumption and increases duration of heating process. In addition, slow rate heating leads to low total pore volume and surface area and non-homogenous microstructure of waste tire activated carbon. The temperature used for heating process range of $500-975^{\circ} \mathrm{C}$ and majority of studies yield surface area of WT-AC less than $600 \mathrm{~m}^{2} / \mathrm{g}$. One of the alternative techniques adapted for conventional heating process is microwave heating, but no study that used microwave technique in activation of waste tire has been published. It is recognized that using microwave heating to provide new challenges to develop more surface area of WT-AC, which results in good adsorption capacity.

The modification of WT-AC was carried out by the formation of different types of surface groups using various methods. The main purpose of surface modification is to increase adsorption capacities which yield in long lifespan of activated carbon. Future studies of surface modification can be applied sulfurization and impregnation methods to form new functional groups that favour pollutant's uptake and enhance lifespan of activated carbon. The management of exhausted adsorbent is one of challenge in activated carbon treatment to ensure their sustainable application. Thus, the preferred method for regeneration of WT-AC should be considered for future research.

\subsection{Environmental Impact of Waste Tire Derived Activated Carbon}

The large amount of solid waste generated from tires is becoming a major environmental issue. This is due to improper waste management treatment. Waste tires have high contents of combustible composition and potential for valuable materials and energy resources [95]. Waste tires have a severe negative impact on the environment in terms of air, water, and soil pollution [96]. There are several issues should be addressed concerning waste tires including open dumping (requires large space in landfills), open burning (release harmful chemicals into the air), presence of disease vectors, such as insects, rodents or mosquitoes, leaching (soil contamination). The high composition of harmful chemicals (such as cyanhydric acid, hydrochloric acid, toluene, polycyclic aromatic hydrocarbons, polychlorinated biphenyls) and gaseous (such as carbon dioxide, carbon monoxide, nitrous oxide, nitric oxide, sulfur oxide) released through the combustion of tyres is a big concern [97]. 
As mentioned earlier, waste tire-derived activated carbon has produced high quality activated carbons and achieves high removal efficiency. The waste tire-derived activated carbons contained high concentrations of sulphur and zinc, as well as traces of other metals such as lead, cadmium, chromium and molybdenum. Thus, the leaching of some of these species may limit their use in various applications specifically in drinking or water treatment. However, this problem can be controlled by carried out leaching test to remove the inorganic species. For example, San Miguel et al. [98] performed a leaching test of inorganic species for waste tire-derived activated carbons at various $\mathrm{pH}$ values. The authors confirmed that the values of concentration levels of all species were below limit values of WHO drinking waters standard. In another study, Selbes et al. [99] investigated the leaching of selected inorganic and organics constituents from waste tire. They performed a systematic study of leaching test and suggested the best alternative solutions for managing of waste tires.

\section{Conclusion and Future Perspectives}

The conversion of waste material to valuable products could reduce the environmental pollution and disposal problem. The application of modified activated carbon from waste tire rubber has been widely studied at the laboratory scale for the removal of dye and heavy metals through the adsorption method. However, there is still diminutive information on a full study pertaining to the waste tire as adsorbent in the gas separation application to remove air pollutants. This would be useful in the development of a detailed techno-economic analysis of waste tire. In this review, a substantial number of relevant published articles of waste tired activated carbon for the removal of pollutant in liquid and air have been reviewed. Waste tire activated carbon has been found to be efficient in removing different type of organic, dyes and heavy metals from wastewater. Furthermore, waste tire activated carbon has been verified as good adsorbent to remove air pollutants such as $\mathrm{CO}_{2}, \mathrm{SO}_{2}$ and $\mathrm{NOx}$. The chemical modification of surface waste tire activated carbon can increase the surface are, thereby, increasing adsorption capacity. In future research, the studies should be scaled-up to a large-scale using waste tire activated carbon to evaluate their performance in removing pollutants from wastewater or air. Pilot scale studies can also be used to complete the life cycle assessment of modified waste tire adsorbent to be compared with commercial sorbents including adsorbent stability and regeneration/reuse cycles. In addition, the cost of the precursor, final product of waste tire activated carbon and regeneration process is important to evaluate. If the waste tire activated carbon is not regenerated, the exhausted adsorbent is required handled as hazardous waste. However, cost comparison between the commercial carbon and porous-carbon adsorbents produced from waste rubber tires is crucial in order to evaluate their utility in adsorption process from the economic point of view. Still, more research efforts have to be made to significantly improve the properties and performance of waste rubber tire. Overall, waste tire activated carbon has significant advantages as alternative activated carbon for liquid and air pollution control and can minimize the waste volume produced from the disposed tires.

\section{Acknowledgment}

The authors acknowledged the financial support from the CRG-UTP-UniMAP grant (9023-00023) and Loreal-UNESCO FWIS 2020 grant (9008-00018).

\section{Author Contributions}

U.F.M.A (Associate Professor) visualized, wrote, reviewed and edited the original draft. F.H. (Ph.D) wrote and edited the manuscript. S.C.B.G (Associate Professor) wrote and edited the manuscript. M.K.A (Professor) reviewed and edited the manuscript. M.H.K (Ph.D) wrote and revised the manuscript. N.J. (Ph.D) reviewed and proofread the manuscript. N.I. (Associate Professor) reviewed and edited the manuscript. S.F.K.A (MSc) wrote and edited the manuscript.

\section{References}

1. Hita I, Arabiourrutia M, Olazar M, Bilbao J, Arandes JM, Castaño P. Opportunities and barriers for producing high quality fuels from the pyrolysis of scrap tires. Renew. Sust. Energ. Rev. 2016;56:745-759.

2. Shahrokhi-Shahraki R, Kwon PS, Park J, O'Kelly BC, Rezania S. BTEX and heavy metals removal using pulverized waste tires in engineered fill materials. Chemosphere 2020;242:125281.

3. Abbaspour M, Aflaki E, Nejad FM. Reuse of waste tire textile fibers as soil reinforcement. J. Clean. Prod. 2019;207:1059-1071.

4. Boon KH, Yeoh D, Jamaluddin N. Properties of pervious concrete containing scrap tyre tubes. MATEC Web Conf. 2017;103:01015.

5. T Saleh TA, Gupta VK. Processing methods, characteristics and adsorption behavior of tire derived carbons: a review. $A d v$. Colloid. Interface. Sci. 2014;211:93-101.

6. Godlewska J. Recovery and recycling of waste tires in Poland. Procedia Eng. 2017;182:229-234.

7. Torretta V, Rada EC, Ragazzi M, Trulli E, Istrate IA, Cioca LI. Treatment and disposal of tyres: Two EU approaches. A review. Waste manage. 2015;45:152-160.

8. Czajczyńska D, Krzyżyńska R, Jouhara H, Spencer N. Use of pyrolytic gas from waste tire as a fuel: A review. Energy. 2017;134:1121-1131.

9. Martínez JD, Murillo Villuendas R, García T. Production of carbon black from the waste tires pyrolysis. Bol. Grupo Español Carbón. 2013;30:10-14.

10. Kumaravel ST, Murugesan A, Kumaravel A. Tyre pyrolysis oil as an alternative fuel for diesel engines-A review. Renew. Sust. Energ. Rev. 2016;60:1678-1685.

11. Umi Fazara MA, Jainoo I, Ismail KN, Hussin K, Fahmi MR. Physicochemical Properties of Pyrolitic Carbon Black from Waste Tyres. Key Eng. Mater. 2014;594:178-182.

12. Paul TW. Pyrolysis of waste tyres: a review. Waste Manag. 2013;33:1714-1728.

13. Pilusa J, Muzenda E. Beneficiation of pyrolitic carbon black. Int. J. Chem. Nucl. Mater. Metall. Eng. 2013;7(10):392-396.

14. Acosta R, Nabarlatz D, Sánchez-Sánchez A, Jagiello J, Gadonneix 
P, Celzard A, Fierro V. Adsorption of Bisphenol A on KOH-activated tyre pyrolysis char. J. Environ. Chem. Eng. 2018;6(1): 823-833.

15. Jahanbakhsh F, Ebrahimi B. Modified activated carbon with zinc oxide nanoparticles produced from used tire for removal of acid green 25 from aqueous solutions. Am. j. appl. chem. 2016;4(1):8-13.

16. Sugatri RI, Wirasadewa YC, Saputro KE, Muslih EY, Ikono R, Nasir M. Recycled carbon black from waste of tire industry: thermal study. Microsyst. Technol. 2018;24(1):749-755.

17. Lu Q, de Toledo RA, Xie F, Li J, Shim H. Reutilization of waste scrap tyre as the immobilization matrix for the enhanced bioremoval of a monoaromatic hydrocarbons, methyl tert-butyl ether, and chlorinated ethenes mixture from water. Sci. Total Environ. 2017;583:88-96.

18. Makrigianni V, Giannakas A, Deligiannakis Y, Konstantinou I. Adsorption of phenol and methylene blue from aqueous solutions by pyrolytic tire char: equilibrium and kinetic studies. J. Environ. Chem. Eng. 2015;3(1):574-582.

19. V Gupta VK, Nayak A, Agarwal S, Chaudhary M, Tyagi I. Removal of $\mathrm{Ni}$ (II) ions from water using scrap tire. J. Mol. Liq. 2014;190:215-222.

20. Lin JH, Wang SB. An effective route to transform scrap tire carbons into highly-pure activated carbons with a high adsorption capacity of ethylene blue through thermal and chemical treatments. Environ. Technol. Innov. 2017;8:17-27.

21. Gupta VK, Nayak A, Agarwal S, Tyagi I. Potential of activated carbon from waste rubber tire for the adsorption of phenolics: effect of pre-treatment conditions. J. Colloid. Interface. Sci. 2014;417:420-430.

22. Karmacharya MS, Gupta VK, Tyagi I, Agarwal S, Jha VK. Removal of As (III) and As (V) using rubber tire derived activated carbon modified with alumina composite. J. Mol. Liq. 2016;216:836-844.

23. Karmacharya MS, Gupta VK, Jha VK. Preparation of activated carbon from waste tire rubber for the active removal of $\mathrm{Cr}$ (VI) and Mn (II) ions from aqueous solution. Trans. Indian Inst. Met. 2016;75(4):234-241.

24. Bhatti IA, Ahmad N, Iqbal N, Zahid M, Iqbal M. Chromium adsorption using waste tire and conditions optimization by response surface methodology. J. Environ. Chem. Eng. 2017;5(3):2740-2751.

25. Nieto-Márquez A, Pinedo-Flores A, Picasso G, Atanes E, Kou RS. Selective adsorption of $\mathrm{Pb} 2+, \mathrm{Cr} 3+$ and $\mathrm{Cd} 2+$ mixtures on activated carbons prepared from waste tires. J. Environ. Chem. Eng. 2017;5(1):1060-1067.

26. Mouzourakis E, Georgiou Y, Louloudi M, Konstantinou I, Deligiannakis Y. Recycled-tire pyrolytic carbon made functional: A high-arsenite As (III). uptake material PyrC350®. J. Hazard. Mater. 2017;326:177-186.

27. Ramarad S, Khalid M, Ratnam CT, Chuah AL, Rashmi W. Waste tire rubber in polymer blends: A review on the evolution, properties and future. Prog. Mater. Sci. 2015;72:100-140.

28. Thomas BS, Gupta RC. A comprehensive review on the applications of waste tire rubber in cement concrete. Renew. Sust. Energ. Rev. 2016;54:1323-1333.

29. Kashani A, Ngo TD, Hemachandra P, Hajimohammadi A. Effects of surface treatments of recycled tyre crumb on cement-rubber bonding in concrete composite foam. Constr Build Mater. 2018;171:467-473.

30. Abbaspour M, Aflaki E, Nejad FM. Reuse of waste tire textile fibers as soil reinforcement. J. Clean. Prod. 2019;207:1059-1071.

31. Sofi A. Effect of waste tyre rubber on mechanical and durability properties of concrete-A review. Ain Shams Eng. J. 2018;9(4): 2691-2700.

32. Mohajerani A, Burnett L, Smith JV, Markovski S, Rodwell G, Rahman MT, Kurmus H, Mirzababaei M, Arulrajah A, Horpibulsuk S, Maghool F. Recycling waste rubber tyres in construction materials and associated environmental considerations: A review. Resour. Conserv. Recycl. 2020;155:104679.

33. Gupta VK, Ali I, Saleh TA, Siddiqui MN, Agarwal S. Chromium removal from water by activated carbon developed from waste rubber tires. Environ. Sci. Pollut. Res. 2013;20(3):1261-1268.

34. He L, Ma Y, Liu Q, Mu Y. Surface modification of crumb rubber and its influence on the mechanical properties of rubber-cement concrete. Constr. Build. Mater. 2016;120:403-407.

35. Fraile-Garcia E, Ferreiro-Cabello J, Mendivil-Giro M, San Vicente-Navarro A. Thermal behaviour of hollow blocks and bricks made of concrete doped with waste tyre rubber. Constr. Build. Mater. 2018;176:193-200.

36. Chaikaew C, Sukontasukkul P, Chaisakulkiet U, Sata V, Chindaprasirt P. Properties of concrete pedestrian blocks containing crumb rubber from recycle waste tyres reinforced with steel fibres. Case Stud. Constr. Mater. 2019;11:e00304.

37. Bekhiti M, Trouzine H, Rabehi M. Influence of waste tire rubber fibers on swelling behavior, unconfined compressive strength and ductility of cement stabilized bentonite clay soil. Constr Build Mater. 2019;208:304-313.

38. Shukla T, Mistry M, Solanki C, Shukla SK, Shukla S. Influence of randomly distributed waste tire fibres on swelling behaviour of expansive soils. In: Madhavi Latha Gali, P.Raghuveer Rao, eds. Problematic Soils and Geoenvironmental Concerns. Springer; 2021. p. 319-332.

39. Liu L, Cai G, Zhang J, Liu X, Liu K. Evaluation of engineering properties and environmental effect of recycled waste tire-sand/soil in geotechnical engineering: A compressive review. Renew. Sust. Energ. Rev. 2020;126:109831.

40. Moo-Young H, Sellasie K, Zeroka D, Sabnis G. Physical and chemical properties of recycled tire shreds for use in construction. J. Environ. Eng. 2003;129(10):921-929.

41. Shalaby A, Khan RA. Design of unsurfaced roads constructed with large-size shredded rubber tires: a case study. Resour. Conserv. Recycl. 2005;44(4):318-332.

42. Yang Z, Zhang Q, Shi W, Lv J, Lu Z, Ling X. Advances in properties of rubber reinforced soil. Adv. Civ. Eng. 2020;20202: 6629757.

43. Ghodake GS, Shinde SK, Kadam AA, et al. Review on biomass feedstocks, pyrolysis mechanism and physicochemical properties of biochar: State-of-the-art framework to speed up vision of circular bioeconomy. J. Clean. Prod. 2021:126645.

44. Mui EL, Ko DC, McKay G. Production of active carbons from waste tyres-a review. Carbon. 2004;42(14):2789-2805.

45. Saleh TA, Al-Saadi AA, Gupta VK. Carbonaceous adsorbent prepared from waste tires: experimental and computational evaluations of organic dye methyl orange. J. Mol. Liq. 2014;191: 
85-91.

46. Betancur M, Martínez JD, Murillo R. Production of activated carbon by waste tire thermochemical degradation with $\mathrm{CO} 2$. J. Hazard. Mater. 2009;168(2-3):882-887.

47. Choi GG, Jung SH, Oh SJ, Kim JS. Total utilization of waste tire rubber through pyrolysis to obtain oils and CO2 activation of pyrolysis char. Fuel Process. Technol. 2014;123:57-64.

48. Alsaleh A, Sattler ML. Waste tire pyrolysis: influential parameters and product properties. Renew. Energ. 2014;1(4):129-135.

49. González-González RB, Ruiz-Gómez N, Gea G, et al. Valorization of Waste Tires by Pyrolysis and Activation Processes. Appl. Sci. 202;11(14):6342.

50. Acosta R, Fierro V, De Yuso AM, Nabarlatz D, Celzard A. Tetracycline adsorption onto activated carbons produced by $\mathrm{KOH}$ activation of tyre pyrolysis char. Chemosphere. 2016;149: 168-176.

51. K Dimpe KM, Ngila JC, Nomngongo PN. Application of waste tyre-based activated carbon for the removal of heavy metals in wastewater. Cogent Eng. 2017;4(1):1330912.

52. T Saleh TA, Danmaliki GI. Adsorptive desulfurization of dibenzothiophene from fuels by rubber tyres-derived carbons: kinetics and isotherms evaluation. Process Saf Environ Prot. 2016;102:9-19.

53. Acevedo B, Barriocanal C. Texture and surface chemistry of activated carbons obtained from tyre wastes. Fuel Process. Technol. 2015;134:275-283.

54. A Al-Rahbi AS, Williams PT. Production of activated carbons from waste tyres for low temperature NOx control. Waste Manage. 2016;49:188-195.

55. Al-Saadi AA, Saleh TA, Gupta VK. Spectroscopic and computational evaluation of cadmium adsorption using activated carbon produced from rubber tires. J. Mol. Liq. 2013;188:136-142.

56. Belgacem A, Rebiai R, Hadoun H, Khemaissia S, Belmedani M. The removal of uranium (VI) from aqueous solutions onto activated carbon developed from grinded used tire. Environ. Sci. Pollut. Res. 2014;21(1):684-694.

57. Dimpe KM, Mpupa A, Nomngongo PN. Microwave assisted solid phase extraction for separation preconcentration sulfamethoxazole in wastewater using tyre based activated carbon as solid phase material prior to spectrophotometric determination. Spectrochim. Acta A Mol. Biomol. Spectrosc. 2018;188:341-348.

58. Dong P, Maneerung T, Ng WC, et al. Chemically treated carbon black waste and its potential applications. J. Hazard. Mater. 2017;321:62-72.

59. Gupta VK, Nayak A, Agarwal S. Performance evaluation and application of oxygen enriched waste rubber tire adsorbent for the removal of hazardous aniline derivatives from waste water. Chem. Eng. J. 2012;203:447-457.

60. Gupta VK, Gupta B, Rastogi A, Agarwal S, Nayak A. A comparative investigation on adsorption performances of mesoporous activated carbon prepared from waste rubber tire and activated carbon for a hazardous azo dye-Acid Blue 113. J. Hazard. Mater. 2011;186(1):891-901.

61. P Hadi P, Yeung KY, Guo J, Wang H, McKay G. Sustainable development of tyre char-based activated carbons with different textural properties for value-added applications. J. Environ. Manage. 2016;170:1-7.
62. F López FA, Centeno TA, Rodríguez O, Alguacil FJ. Preparation and characterization of activated carbon from the char produced in the thermolysis of granulated scrap tyres. J. Air Waste Manag. 2013;63(5):534-544.

63. Wang ZB, Tian YJ, Wang XK. Adsorption Performance to Methylene Blue by Non-activated Tire-based Pyrolytic Char. Appl. Mech. Mater. 2014;508:35-39.

64. Acevedo B, Rocha RP, Pereira MF, Figueiredo JL, Barriocanal C. Adsorption of dyes by ACs prepared from waste tyre reinforcing fibre. Effect of texture, surface chemistry and pH. J. Colloid. Interface. Sci. 2015;459:189-198.

65. Saleh TA, Gupta VK, Al-Saadi AA. Adsorption of lead ions from aqueous solution using porous carbon derived from rubber tires: Experimental and computational study. J. Colloid. Interface. Sci. 2013;396:264-269.

66. Alexandre-Franco M, Fernández-González C, Alfaro-Domínguez M, Gómez-Serrano V. Adsorption of cadmium on carbonaceous adsorbents developed from used tire rubber. J. Environ. Manage. 2011;92(9):2193-2200.

67. Siddiqui MN, Redhwi HH, Al-Saadi AA, Rajeh M, Saleh TA. Kinetic and computational evaluation of activated carbon produced from rubber tires toward the adsorption of nickel in aqueous solutions. Desal. Water Treat. 2016;57(37):17570-17578.

68. Mashile GP, Mpupa A, Nqombolo A, Dimpe KM, Nomngongo PN. Recyclable magnetic waste tyre activated carbon-chitosan composite as an effective adsorbent rapid and simultaneous removal of methylparaben and propylparaben from aqueous solution and wastewater. J. Water Process Eng. 2020;33:101011.

69. Babiker E, Al-Ghouti MA, Zouari N, McKay G. Removal of boron from water using adsorbents derived from waste tire rubber. J. Environ. Chem. Eng. 2019;7(2):102948.

70. M Prakash MO, Raghavendra G, Ojha S, Panchal M. Characterization of porous activated carbon prepared from arhar stalks by single step chemical activation method. Mater. Today. 2021;39:1476-1481.

71. Jusoh NW, Choo TY, Masudi A, Ali RR. Waste Tire Carbon Adsorbent for Active Removal of Paracetamol in Aqueous Solution. J. Phys. Conf. Ser. 2020;1447(1):012050.

72. Islam MT, Saenz-Arana R, Hernandez C, et al. Conversion of waste tire rubber into a high-capacity adsorbent for the removal of methylene blue, methyl orange, and tetracycline from water. J. Environ. Chem. Eng. 2018;6(2):3070-3082.

73. Hamdi A, Abdelaziz G, Farhan KZ. Scope of reusing waste shredded tires in concrete and cementitious composite materials: A review. J. Build. Eng. 2020:102014.

74. Jones I, Zhu M, Zhang J, et al. The application of spent tyre activated carbons as low-cost environmental pollution adsorbents: a technical review. J. Clean. Prod. 2021:127566.

75. Lin C, Huang CL, Shern CC. Recycling waste tire powder for the recovery of oil spills. Resour. Conserv. Recycl. 2008;52(10): 1162-1166.

76. Nuzaimah M, Sapuan SM, Nadlene R, Jawaid M. Recycling of waste rubber as fillers: A review. In: The Wood and Biofiber International Conference (WOBIC 2017); 21-23 November 2017; Selangor, Malaysia. IOP Conf. Ser. Mater. Sci. Eng. 2018;368(1): 012016.

77. Nogueira M, Matos I, Bernardo M, et al. Char from Spent Tire 
Rubber: A Potential Adsorbent of Remazol Yellow Dye. $C$ J. Carbon. Res. 2019;5(4):76.

78. Zhang Y, Ji G, Li C, Wang X, Li A. Templating synthesis of hierarchical porous carbon from heavy residue of tire pyrolysis oil for methylene blue removal. Chem. Eng. J. 2020;390:124398.

79. Rungrodnimitchai S, Kotatha D. Chemically modified ground tire rubber as fluoride ions adsorbents. Chem. Eng. J. 2015;282:161-169.

80. Al-Asheh S, Banat F. Adsorption of copper ions on to tyre rubber. Adsorp. Sci. Technol. 2000;18(8):685-700.

81. Mousavi HZ, Hosseynifar A, Jahed V, Dehghani SA. Removal of lead from aqueous solution using waste tire rubber ash as an adsorbent. Braz. J. Chem. Eng. 2010;27(1):79-87.

82. Ramola S, Mishra T, Rana G, Srivastava RK. Characterization and pollutant removal efficiency of biochar derived from baggase, bamboo and tyre. Environ. Monit. Assess. 2014;186(12): 9023-9039.

83. Imyim A, Sirithaweesit T, Ruangpornvisuti V. Arsenite and arsenate removal from wastewater using cationic polymer-modified waste tyre rubber. J. Environ. Manage. 2016;166:574-578.

84. Chang NB, Houmann C, Lin KS, Wanielista M. Fate and transport with material response characterization of green sorption media for copper removal via adsorption process. Chemosphere. 2016;144:1280-1289.

85. Deng Y, Morris C, Rakshit S, Landa E, Punamiya P, Sarkar D. Water treatment residuals and scrap tire rubber as green sorbents for removal of stormwater metals. Water Environ. Res. 2016;88(6):500-509.

86. Song M, Wei Y, Yu L, Tang X. The application of prepared porous carbon materials: Effect of different components on the heavy metal adsorption. Waste Manag. Res. 2016;34(6):534-541.

87. Benjamin SE, Sajjid MA. Factors Affecting the Adsorption of Trivalent Chromium Ions by Activated Carbon Prepared from Waste Rubber Tyres. Adv. Sci. Technol. Eng. Syst. 2017;2:16601664.

88. Guerrero-Esparza MM, Medina-Valtierra J, Carrasco-Marín F. Chars from waste tire rubber by catalytic pyrolysis and the statistical analysis of the adsorption of Fe in potable water. Environ. Prog. Sustain. Energy. 2017;36(6):1794-1801.

89. Dimpe KM, Ngila JC, Nomngongo PN. Preparation and application of a tyre-based activated carbon solid phase extraction of heavy metals in wastewater samples. Phys Chem. Earth, Parts A/B/C. 2018;105:161-169.

90. Adathodi L, Raja Murugadoss J, Gaddam K. Application of a novel adsorbent- aircraft tyre rubber ash for the removal of chromium from wastewaters. Rasayan J. Chem. 2018;11:1204-1210.

91. Nieto-Márquez A, Atanes E, Morena J, Fernández-Martínez F, Valverde JL. Upgrading waste tires by chemical activation for the capture of SO2. Fuel Process Technol. 2016;144:274-281.

92. T Brady TA, Rostam-Abadi M, Rood MJ. Applications for activated carbons from waste tires: natural gas storage and air pollution control. Gas. Separ. Purif. 1996;10(2):97-102.

93. Tang X, Song M, Lei Y, Wang X. Comparison and application of different component municipal solid wastes based carbon on adsorption of carbon dioxide. Int. J. Green Energy. 2017;14(2):135-140.

94. D Krishnaiah D, Bono A, Sarbatly R, Nithyanandam R, Anisuzzaman SM. Optimisation of spray drying operating conditions of Morinda citrifolia L. fruit extract using response surface methodology. J. King Saud Univ. Eng. Sci. 2015;27(1):26-36.

95. Mmereki D, Machola B, Mokokwe K. Status of waste tires and management practice in Botswana. J. Air Waste Manag. 2019;69(10):1230-1246.

96. Piotrowska K, Kruszelnicka W, Bałdowska-Witos P, et al. Assessment of the environmental impact of a car tire throughout its lifecycle using the lca method. Materials 2019;12(24):4177.

97. Czajczyńska D, Czajka K, Krzyżyńska R, Jouhara H. Waste tyre pyrolysis-Impact of the process and its products on the environment. Therm. Sci. Eng. Prog. 2020;20:100690.

98. San Miguel G, Fowler GD, Sollars CJ. The leaching of inorganic species from activated carbons produced from waste tyre rubber. Water Res. 2002;36(8):1939-1946.

99. Selbes M, Yilmaz O, Khan AA, Karanfil T. Leaching of DOC, $\mathrm{DN}$, and inorganic constituents from scrap tires. Chemosphere 2015;139:617-623. 